\title{
Induction of early pregnancy factor activity in vitro by platelet-activating factor in mice
}

\author{
G. E. Lash and M. Legge* \\ Department of Biochemistry, University of Otago, PO Box 56, Dunedin, New Zealand
}

\begin{abstract}
The rosette inhibition test was used to determine early pregnancy factor activity in culture media from oestrous mouse ovaries and oviducts stimulated in vitro for early pregnancy factor production under different experimental conditions. Embryo conditioned media, platelet-activating factor and cortical granule release media could all stimulate the production of early pregnancy factor by oestrous mouse ovaries and oviducts. This stimulation was completely blocked by the presence of BN 52021, a platelet-activating factor receptor antagonist. This study indicates that platelet-activating factor is the 'ovum factor' released by the zygote on fertilization to initiate the synthesis of early pregnancy factor.
\end{abstract}

\section{Introduction}

Early pregnancy factor (EPF) is one of the earliest biochemical indicators of pregnancy (Morton et al., 1974). It has been detected at about the time of the pronuclear stage of the embryo in all mammals investigated including mice (Morton et al., 1974), humans (Morton et al., 1977), several domestic (Morton ef al., 1979; Nancarrow et al., 1981) and exotic species (H. Morton, personal communication). Cavanagh et al. (1982) proposed that the synthesis of EPF was initiated by a signal from the fertilized ovum ('ovum factor') and subsequently demonstrated that oestrous mouse ovaries and oviducts together in culture could be induced to release EPF in response to the addition of embryo conditioned media (ECM, a source of 'ovum factor') and prolactin to the culture media (Cavanagh, 1984), thereby confirming that the maternal ovaries are the initial site of EPF production.

In mice and humans fertilization induces a pregnancyassociated thrombocytopenia (O'Neill, 1985a) which has been attributed to the release of platelet-activating factor (PAF) by the zygote (O'Neill, 1985b,c). Ammit and O'Neill (1991) subsequently confirmed the release of embryonic PAF into culture media, and O'Neill and Saunders (1984) identified a correlation between media PAF concentration, embryo implantation rate and successful pregnancy. Orozco et al. (1986) injected PAF into mature female mice at four stages of the oestrous cycle, mature male mice and immature female mice. Only animals that were in dioestrus, pro-oestrus or oestrus gave a positive EPF result within $1 \mathrm{~h}$ of injection. This group also demonstrated that PAF in combination with oestrous mouse serum could give a positive response in the rosette inhibition test (Orozco et al., 1990). They went on to show that soluble factors ( $\mathrm{S} 2$ factors) were produced by the spleen cell population in response to the PAF and that they came from the

*Correspondence.

Received 1 May 1996. lipoxygenase pathway (Clarke et al., 1990). Sueoka et al. (1988) investigated whether the administration of PAF to rabbits would stimulate the production of EPF and, if so, which organs were involved. Concentrations of EPF were measured after the administration of synthetic PAF to intact rabbits (i.v. injection into the marginal ear vein), rabbits after bilateral salpingooophorectomy and isolated in vitro perfused rabbit ovary or oviduct. Serum EPF was detected 30 min after PAF injection into intact rabbits; no EPF response was detected from rabbits that had undergone bilateral salpingo-oophorectomy only. From the experiments performed in vitro they found EPF only in the perfusate from both ovaries and oviducts; however, if the perfusates from the two organs perfused separately were combined, a positive EPF response was obtained (Sueoka et al., 1988). All other studies investigating the relationship between PAF and EPF have involved mice as the experimental animal. Cavanagh et al. (1991) carried out similar experiments to Orozco et al. (1986) but compared the efficacy of PAF and ECM to induce an EPF response from whole animals (mice) and in the in vitro culture system (Cavanagh, 1984). They found that ECM and PAF had different reactions in mice; PAF could elicit a response in male as well as female mice and the response time was faster than for ECM, whereas ECM could only elicit a response from female mice. In their in vitro culture system PAF could not elicit an EPF response.

\section{Materials and Methods}

\section{Animals}

Mature $\mathrm{C} 57 \mathrm{BL} / 6 \mathrm{~J} \times \mathrm{BALB} / \mathrm{cJ}$ and $\mathrm{BALB} / \mathrm{cJ} \times \mathrm{C} 57 \mathrm{BL} / 6 \mathrm{~J} \mathrm{~F}_{1}$ hybrid female mice (6-10 weeks old) were used throughout for the organ culture experiments. Spleens from mature male mice of the same $F_{1}$ hybrids were used for the lymphocyte preparation in the rosette inhibition assay. All animals were killed by cervical dislocation. The animals were housed in cages with 
water and food (Reliance Stock Food Pellets, Dunedin, NZ) ad libitum and were on a $12 \mathrm{~h}$ light: $12 \mathrm{~h}$ dark cycle with lights on at 07:30 h. All animal experiments had animal ethics committee approval.

\section{Determination of oestrus}

Animal cyclicity was determined by examination of vaginal smears (van der Salm and Legge, 1994). Those animals in oestrus were killed and dissected under sterile conditions for removal of ovaries and oviducts.

\section{Embryo conditioned media (ECM)}

Mice were superovulated using $12 \mathrm{iu}$ pregnant mares serum gonadotrophin (PMSG, Folligon, Intervet, Pharmaco, Auckland) foliowed $48 \mathrm{~h}$ later by 20 iu hCG (Sigma Chemical Co., St Louis, MO) (Legge and Sellens, 1994). Males were introduced at this stage and females checked for vaginal plugs on the next morning. Animals with vaginal plugs were killed and their embryos collected into embryo culture media. After three washes, the embryos were cultured in Hoppe and Pitts embryo culture media (Hoppe and Pitts, 1973) for 24-48 h at $37^{\circ} \mathrm{C}$ in a $5 \% \mathrm{CO}_{2}$ in air incubator. Media were collected and used either fresh or stored at $-20^{\circ} \mathrm{C}$ until required for use.

\section{Cortical granule release media (CGRM)}

Oocytes were induced to release their cortical granules by the method of Ducibella et al. (1988). Oocytes were collected from superovulated (PMSG/hCG) mice into magnesium- and calcium-free Hoppe and Pitts embryo culture medium. Cumulus cells were removed by treatment with bovine testicular hyaluronidase (Sigma Chemical Co.) and washed three times before they were transferred into media containing $5 \mu \mathrm{mol}$ A23187 $\mathrm{l}^{-1}$ (calcium ionophore, Sigma Chemical Co.) for $2 \mathrm{~min}$. The oocytes were then transferred to fresh media without ionophore and left for $30 \mathrm{~min}$ at $37^{\circ} \mathrm{C}$ in $5 \%$ carbon dioxide in air incubator. This media was taken to contain the products of cortical granule exocytosis and was used either fresh or stored at $-20^{\circ} \mathrm{C}$ until required for use.

\section{Quinacrine embryo conditioned media}

Embryos were collected and incubated in quinacrine (100 $\mu \mathrm{mol} \mathrm{l}^{-1}$, Sigma Chemical Co.) for $24 \mathrm{~h}$ as described by Braquet et al. (1987). The media was collected and stored at $-20^{\circ} \mathrm{C}$ until required for use in the inhibitor studies.

\section{Organ culture}

Five cultures were established for each experimental group. Organ culture of oestrous mouse ovaries and oviducts was established according to the method of Cavanagh (1984). RPMI 1640 tissue culture media (Gibco, Life Technologies, Auckland) containing penicillin (100 units $\mathrm{ml}^{-1}$, Sigma Chemical Co.) and streptomycin (100 $\mu \mathrm{g} \mathrm{ml}^{-1}$, Sigma Chemical Co.) was used throughout. Briefly, ovaries and oviducts were removed from animals in oestrus and immediately placed in sterile Hank's balanced salt solution (HBSS), washed briefly and transferred to RPMI 1640 tissue culture media containing penicillin (100 units $\mathrm{ml}^{-1}$ ) and streptomycin $\left(100 \mu \mathrm{g} \mathrm{ml}^{-1}\right)$. Both sets of ovaries and oviducts from each animal were cultured together in a total of $2 \mathrm{ml}$ of culture media. The cultures were maintained in a humidified atmosphere of $5 \%$ carbon dioxide in air at $37^{\circ} \mathrm{C}$ for $24 \mathrm{~h}$. The media were then collected and replaced with fresh RPMI 1640 containing the agents (PAF, ECM or CGRM) to be tested both in the presence and absence of prolactin (sheep, $0.2 \mu \mathrm{g}$, Sigma Chemical Co.). The agents were used at the following concentrations: $0.2 \mathrm{ng}$ platelet-activating factor (Sigma Chemical Co.), $50 \mu \mathrm{l}$ ECM, and $50 \mu \mathrm{l}$ CGRM. PAF receptor antagonist (BN 52021, $10 \mathrm{nmol} \mathrm{I}^{-1}$, Sigma Chemical Co.) was added at the same time as the PAF, ECM and CGRM in the inhibitor experiments. The cultures were incubated for $48 \mathrm{~h}$ and the medium was then replaced once more with the same additives. All media were collected and stored at $-20^{\circ} \mathrm{C}$ until required for assaying in the rosette inhibition test. Ovaries and oviducts were also cultured separately, and each of the agents was tested but not with the inhibitors. Control cultures contained either ovaries and oviducts, ovaries alone or oviducts alone with culture media alone or in the presence of prolactin.

\section{Rosette inhibition test}

EPF was assayed using the rosette inhibition test as established by Morton et al. (1974) and adapted by Rolfe et al. (1984) using mouse lymphocytes, a rabbit anti-mouse antilymphocyte serum and human red blood cells. This assay has been previously described by Lash and Legge (1994). Briefly, lymphocytes were isolated from mouse spleens according to Rolfe et al. (1984). The spleens from male BALB/cJ $\times$ C57BL/6J $\mathrm{F}_{1}$ or $\mathrm{C} 57 \mathrm{BL} / 6 \mathrm{~J} \times \mathrm{BALB} / \mathrm{cJ} \mathrm{F}_{1}$ mice were used throughout these investigations. Rabbit anti-mouse anti-lymphocyte serum was raised according to Morton et al. (1975) using lymphocytes from $\mathrm{BALB} / \mathrm{cJ} \times \mathrm{C} 57 \mathrm{BL} / 6 \mathrm{~J} \mathrm{~F}_{1}$ and $\mathrm{C} 57 \mathrm{BL} / 6 \mathrm{~J} \times \mathrm{BALB} / \mathrm{cJ} \mathrm{F}_{1}$ male mice. Human red blood cells were collected fresh each day by finger prick from the same donor and washed three times in Hank's balanced salt solution (HBSS). Guinea-pig complement was purchased from Serotec Ltd. (Oxford). The rosette inhibition titre is taken as the highest dilution of anti-lymphocyte serum (ALS) in which the number of rosettes is less than $75 \%$ of the number found in the two control tubes. This titre is expressed as $\log _{2}$ (reciprocal ALS dilution) $\times 10^{-7}$. A sample is positive for EPF if it has a rosette inhibition titre >14 (Rolfe et al., 1984). The rosette inhibition test is not a quantitative assay. A sample is either positive or negative for EPF activity; the concentration of EPF activity in an assay cannot be measured.

\section{Results}

\section{Oestrous ovaries and oviducts cultured together}

Oestrous ovaries and oviducts were cuitured with ECM, PAF, CGRM with or without prolactin and BN 52021. ECM induced EPF activity in the culture system only in the presence of prolactin. PAF could induce EPF activity in the culture system both in the presence and absence of prolactin (Table 1). 
Table 1. Early pregnancy factor (EPF) response to mouse oestrous ovary and oviduct culture in vitro

\begin{tabular}{lcll}
\hline & Prolactin & $\begin{array}{c}\text { RPMI I640 } \\
\text { EPF response }\end{array}$ & $\begin{array}{c}\text { BN 52021 } \\
\text { EPF response }\end{array}$ \\
\hline RPMI 1640 & + & Negative & $\begin{array}{c}\text { Negative } \\
\text { ECM }\end{array}$ \\
& + & Negative & $\begin{array}{c}\text { Negative } \\
\text { PAF }\end{array}$ \\
& + & Positive & Negative \\
CGRM & + & Negative & Negative \\
& - & Positive & Negative \\
& + & Positive & Negative \\
& - & Negative & Negative \\
\hline
\end{tabular}

ECM: embryo conditioned media; PAF: platelet activating factor; CGRM: cortical granule release media.

$n=5$ for each group.

CGRM had a similar pattern of action as the ECM and could induce EPF activity only in the presence of prolactin. No EPF activity was detected in any of the cultures that contained RPMI 1640 alone or that were in the presence of prolactin alone. There was no EPF activity in any of the cultures that contained trace amounts of A23187. When the same series of cultures were established in the presence of BN 52021 (a PAF receptor antagonist), the ability of ECM, PAF and CGRM to induce EPF activity was abolished completely, regardless of the presence of prolactin (Table 1).

Media was collected from embryos that had been cultured in the presence of quinacrine (an inhibitor of phospholipase $A_{2}$ involved in PAF biosynthesis), which was used in the in vitro culture system for the production of EPF. No EPF activity was detected in these cultures either in the presence or absence of prolactin. We have no evidence to suggest that quinacrine affects the rosette inhibition test itself.

For each experimental group all media tested gave identical EPF results.

\section{Oestrous ovaries and oviducts cultured separately}

The site of EPF production was determined by culturing oestrous ovaries and oviducts separately with ECM, PAF and CGRM with and without prolactin. EPF was not present in any of the oestrous oviduct cultures with ECM, PAF or CGRM with or without prolactin. The pattern of detectable EPF activity from the cultures with oestrous ovaries alone was identical to that of oestrous ovaries and oviducts cultured together (Table 2) except after treatment with CGRM. In the cultures with ECM, EPF activity was detectable only in the presence of prolactin. Both the PAF and CGRM induced a positive EPF response regardless of the presence or absence of prolactin.

For each experimental group all media tested gave identical EPF results.

\section{Discussion}

The chemical nature of the EPF inducing 'ovum factor' has not been elucidated, although several studies have attempted to do
Table 2. Early pregnancy factor (EPF) response to mouse oestrous ovary culture in vitro

\begin{tabular}{lcl}
\hline & Prolactin & EPF Response \\
\hline \multirow{2}{*}{ RPMI 1640} & + & Negative \\
\multirow{2}{*}{ ECM } & - & Negative \\
& + & Positive \\
PAF & - & Negative \\
& + & Positive \\
CGRM & - & Positive \\
& + & Positive \\
& - & Positive \\
\hline
\end{tabular}

ECM: embryo conditioned media; PAF: platelet-activating factor; CGRM: cortical granule release media.

$n=5$ for each group.

this. At present only one definitive candidate molecule, PAF, has been investigated. This lipid is very potent in its activity and is known to be released by preimplantation embryos (Battye et al., 1991). Several studies have investigated the relationship between PAF and EPF, and different conclusions have been presented. Cavanagh et al. (1991) concluded that there was no relationship between PAF and 'ovum factor' since they gave different responses in vivo, in mice and in an in vitro culture system. They identified a positive response to PAF in female and male mice (with ECM only positive in female mice) and the time course of activation of EPF was different between mice injected with PAF and ECM (PAF induced EPF activity was first detectable at $1 \mathrm{~h}$ after injection, had declined significantly by $2 \mathrm{~h}$ after injection and was completely abolished by $3 \mathrm{~h}$ after injection; ECM induced EPF activity, however, was first detectable at $2 \mathrm{~h}$ after injection and increased up to $6 \mathrm{~h}$ after injection). However, Sueoka et al. (1988) and Orozco et al. (1986) both concluded that PAF and 'ovum factor' were identical.

Contrary to the results of Cavanagh et al. (1991), we were able to demonstrate the activation of EPF release from oestrous ovaries and oviducts in culture in the presence of PAF. It must be noted here that the concentration of PAF used in this study was ten times greater than that used by Cavanagh et al. (1991), although it was comparable to the concentrations described in embryo culture media (Ammit and O'Neill, 1991). The other difference between the culture system of Cavanagh et al. (1991) and our system was the media used and the presence of bovine serum albumin (BSA) in their media. The culture media should not affect the system since in the original report of this culture system (Cavanagh, 1984) RPMI 1640 was used. The effect of BSA in the culture media is, however, more significant. BSA is known to bind PAF (Kudolo and Harper, 1990) and inhibit its biological activity. On the basis of BSA:PAF binding studies (Kudolo and Harper, 1990) we consider that there was sufficient BSA in the culture system used by Cavanagh to inhibit the action of PAF on the organs in culture and negate an EPF response.

Further evidence that PAF is the 'ovum factor' comes from the inhibitor studies done with BN 52021. BN 52021 is a specific PAF receptor antagonist and has been used in several studies that have attempted to elucidate the role of PAF in the 
establishment of pregnancy (Acker et al., 1988; Norris et al., 1994; O'Neill, 1995; Velasquez ef al., 1995). When BN 52021 was added to the culture system, no EPF activity was detected in response to any of the agents used: ECM, PAF and CGRM. If PAF was working through its receptor and a second messenger pathway to switch on the synthesis of PAF, it is expected that in the presence of BN 52021 this action of PAF would be inhibited. BN 52021 was also able to inhibit the synthesis of EPF in response to ECM and CGRM, suggesting that whatever they contain that induces the synthesis of EPF also acts through the PAF receptor and in all probability is PAF. Taking together the results that PAF has the same ability as ECM to induce the synthesis of EPF from mouse ovaries and oviducts in culture and that a specific PAF receptor antagonist inhibits this ability, it can be concluded that PAF is the "ovum factor'

To date the origin of the 'ovum factor' has not been investigated, except that it is present in cultures of embryos but not oocytes. Whether it is newly synthesized on fertilization or comes from a store within the oocyte that is released on fertilization has not been documented. We have shown in this study that the 'ovum factor' can be released from oocytes by activation of the cortical granule release pathway. Preliminary data from our laboratory have shown that if the cortical granule reaction is blocked (as seen with the lectin from Lens culinaris), the resultant media cannot induce the synthesis of EPF from the in vitro culture system. It was also shown that embryos can synthesize the 'ovum factor' since incubation with quinacrine inhibited its action. PAF can be synthesized by two different pathways, the 'membrane remodelling pathway' and the 'de novo pathway'. Quinacrine is an inhibitor of phospholipase $A_{2}$, one of the enzymes involved in the "membrane remodelling pathway' for PAF synthesis (Braquet et al., 1987). However, Wells and O'Neill (1992) showed that embryos have the ability to synthesize PAF. In addition, they showed that the final enzymes for both the 'de novo pathway' and the 'membrane remodelling pathway' have been identified in preimplantation embryos (Wells and O'Neill, 1994). The embryos treated with quinacrine were still able to synthesize PAF via the 'de novo pathway'. It is not known whether all PAF synthesis by these embryos was inhibited but they were in a very minimal media with no precursors for the 'de novo pathway' and, if PAF was being produced by this pathway, it may not have been sufficient to induce an EPF response in the in vitro culture system.

The role of prolactin in the culture media is still unclear. Cavanagh $e t$ al. (1982) gave no explanation as to why prolactin was necessary in their culture system, although no EPF response is obtained without it. In contrast to ECM and CGRM, in the case of pure PAF no prolactin was required to give a positive EPF response. Prolactin possibly removes inhibitory substances present in the ECM and CGRM so that they can elicit their action. Further investigations will be required to identify the role of prolactin in this in vitro system and to determine whether this has any relevance to the in vivo situation.

Although the ovaries responded to all three stimuli, the oviducts were unresponsive to all the stimulatory agents, including PAF. This result not only confirms the ovary as the site of EPF production but also suggests that PAF works through the same pathways as ECM and that it is not capable of stimulating all tissue types. O'Neill and Saunders (1984) have shown that the addition of PAF to embryos in vitro enhances their chance of forming a successful pregnancy after embryo transfer. If the in vitro results shown here hold true for the in vivo situation, then this system may be exploited for enhancing the chance of pregnancy for infertile couples. However, if this signalling system can be disrupted it may be a potential target for post-fertilization contraception.

In conclusion, we have shown using an in vitro organ culture system that PAF has the same activity as ECM for EPF production and that this activity can be blocked by the use of a specific PAF receptor antagonist. Furthermore we have confirmed that the ovary is the site of EPF production. This finding supports the earlier in vivo evidence that PAF is 'ovum factor'. We have also shown that the 'ovum factor' is associated with cortical granule release on fertilization and offer further support for a role of PAF in early pregnancy establishment.

The authors are extremely grateful to $\mathrm{H}$. Morton for her help in establishing the rosette inhibition test in our laboratory. This work was supported in part by Otago Medical School Bequest Funds.

\section{References}

Acker G, Hecquet F, Etienne A, Braquet P and Mencia-Huerta JM (1988) Role of platelet-activating factor (PAF) in the ovoimplantation in the rat: effect of the specific PAF-acether antagonist, BN 52021 Prostaglandins 35 233-241

Ammit AJ and O'Neill C (1991) Comparison of a radioimmunoassay and bioassay for embryo-derived platelet-activating factor Human Reproduction 6 872-878

Battye KM, Ammit AJ, O'Neill C and Evans G (1991) Production of plateletactivating factor by the pre-implantation sheep embryo Journal of Reproduction and Fertility 93 507-514

Braquet P, Touqui L, Shen TY and Vargaftig BB (1987) Perspectives in plateletactivating factor research Pharmacological Reviews 39 97-145

Cavanagh AC (1984) Production in vifro of mouse early pregnancy factor and purification to homogeneity Journal of Reproduction and Fertility 71 581-592

Cavanagh AC, Morton H, Rolfe BE and Gidley-Baird AA (1982) Ovum factor: a first signal of pregnancy? American Journal of Reproductive Immunology 2 97-101

Cavanagh AC, Rolfe BE, Athanasas-Platsis S, Quinn KA and Morton H (1991) Relationship between early pregnancy factor, mouse embryo-conditioned medium and platelet-activating factor Journal of Reproduction and Fertility $\mathbf{9 3}$ 355-365

Clarke FM, Orozco C, Perkins AV and Cock I (1990) Partial characterization of the PAF-induced soluble factors which mimic the activity of 'early pregnancy factor' Journal of Reproduction and Fertility 88 459-466

Ducibella T, Anderson E, Albertini DF, Aalberg $\mathbf{J}$ and Rangarajan S (1988) Quantitative studies of changes in cortical granule number and distribution in the mouse oocyte during meiotic maturation Developmental Biology 130 184-197

Hoppe PC and Pitts S (1973) Fertilization in vitro and development of mouse ova Biology of Reproduction 8 420-426

Kudolo GB and Harper MJK (1990) Estimation of platelet-activating factor receptors in the endometrium of the pregnant rabbit: regulation of ligand availability and catabolism by bovine serum albumin Biology of Reproduction $43 \quad 368-377$

Lash GE and Legge M (1994) Effect of superovulation on early pregnancy factor activity in mice Journal of Assisted Reproduction and Genetics 11 320-322

Legge $M$ and Sellens MH (1994) Optimization of superovulation in the reproductively mature mouse Journal of Assisted Reproduction and Genetics 11 312-318

Morton H, Hegh V and Clunie GJA (1974) Immunosuppression detected in pregnant mice by rosette inhibition test Nature 249 459-460 
Morton H, Hegh V and Clunie GJA (1975) Antilymphocyte serum: studies of the specificity of the rosette inhibiting antibody in rabbit anti-mouse ALS Australian Journal of Experimental Biology and Medical Science 53 373-380

Morton H, Rolfe B, Clunie GJA, Anderson MJ and Morrison J (1977) An early pregnancy factor detected in human serum by the rosette inhibition test The Lancet i 394-397

Morton H, Nancarrow CD, Scaramuzzi RJ, Evison BM and Clunie GJA (1979) Detection of early pregnancy in sheep by the rosette inhibition test Journal of Reproduction and Fertility $\mathbf{5 6}$ 75-80

Nancarrow CD, Wallace ALC and Grewal AS (1981) The early pregnancy factor of sheep and cattle Journal of Reproduction and Fertility Supplement 30 191-199

Norris CJ, Peairs WA, Kudolo GB, Newton ER and Harper MJK (1994) Plateletactivating factor antagonists and implantation in rabbits Journal of Reproducfion and Fertility 100 395-401

O'Neill C (1985a) Partial characterization of the embryo-derived plateletactivating factor in mice Journal of Reproduction and Fertility 75 375-380

O'Neill C (1985b) Thrombocytopenia is an initial maternal response to fertilization in mice Journal of Reproduction and Fertility 73 559-566

O'Neill C (1985c) Examination of the causes of early pregnancy-associated thrombocytopenia in mice Journal of Reproduction and Fertility 73 567-577

O'Neill C (1995) Platelet-activating factor-antagonists reduce implantation in mice at low doses only Reproduction, Fertility and Development 7 51-57

O'Neill C and Saunders DM (1984) Assessment of embryo quality The Lancet 2 1035

Orozco C, Perkins T and Clarke FM (1986) Platelet-activating factor induces the expression of early pregnancy factor activity in female mice Journal of Reproduction and Fertility $\mathbf{7 8} 549-555$
Orozco C, Cock I, Perkins AV and Clarke FM (1990) Platelet-activating factor and serum components from oestrous mice co-operate to mimic the activity of 'early pregnancy factor' in the rosette inhibition assay Journal of Reproduction and Fertility 88 447-457

Rolfe B, Cavanagh A, Forde C, Bastin F, Chen C and Morton M (1984) Modified rosette inhibition test with mouse lymphocytes for detection of early pregnancy factor in human pregnancy serum Journal of Immunological Methods 70 1-11

Sueoka K, Dharmarajan AM, Miyazaki Y, Atlas SJ and Wallach EE (1988) Platelet activating factor-induced early pregnancy factor activity from the perfused rabbit ovary and oviduct American Journal of Obstetrics and Gynecology 159 1580-1584

van der Salm LWM and Legge M (1994) A re-evaluation of methods for determining the oestrus cycle in the mouse Animal Technology 45 43-45

Velasquez LA, Aguilera JG and Croxatto HB (1995) Possible role of plateletactivating factor in embryonic signaling during oviductal transport in the hamster Biology of Reproduction 52 1302-1306

Wells XE and O'Neill C (1992) Biosynthesis of platelet-activating factor by two-cell mouse embryos Journal of Reproduction and Fertility 96 61-71

Wells XE and O'Neill C (1994) Detection and preliminary characterization of two enzymes involved in biosynthesis of platelet-activating factor in mouse oocytes, zygotes and preimplantation embryos: dithiothreitol-insensitive cytidinediphosphocholine: 1-O-alkyl-2-acetyl-sn-glycerol cholinephosphotransferase and acetyl-coenzyme A: 1-O-alkyl-2-lyso-sn-glycero-3phosphocholine acetyltransferase Journal of Reproduction and Fertility 101 385-391 